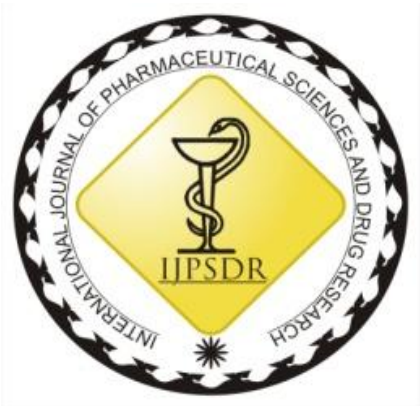

ISSN: 0975-248X

RESEARCH ARTICLE CODEN (USA): IJPSPP

$($ (c) $)$ EY-NC-SA

\title{
Formulation and Evaluation of Benazepril Hydrochloride Transdermal Films for Controlled Drug Release
}

\author{
B. Usha Sri ${ }^{*}$, G. Arjun² \\ ${ }^{1}$ Vijaya College of Pharmacy, Hayath Nagar, Hyderabad - 501511, Telangana, India \\ ${ }^{2}$ Teegala Ram Reddy College of Pharmacy, Pragathi Colony, Meerpet, Hyderabad-500097, Telangana, India
}

Copyright (C) 2019 B. Usha Sri et al. This is an open access article distributed under the terms of the Creative Commons AttributionNonCommercial-ShareAlike 4.0 International License which allows others to remix, tweak, and build upon the work non-commercially, as long as the author is credited and the new creations are licensed under the identical terms.

\begin{abstract}
The current research deals with formulation and evaluation of Benazepril hydrochloride transdermal films, by varying ratios of polymers Eudragit RL100, Eudragit RS100 by film casting technique. Preformulation studies were conducted to check the solubility, melting point and partition coefficient. The eleven formulations were analyzed for physicochemical parameters and drug dissolution potential of transdermal films. All the formulations are transparent with minimum weight variation and uniform thickness. The drug content uniformity of all the formulations vary between $96.84 \pm 3.7 \%$ to $96.98 \pm 1.6 \%$ indicate uniform drug distribution. The low water vapour transmission values indicate good water vapour permeation. The folding endurance is between $246 \pm 4.60$ to $315 \pm$ 4.13 indicates that the transdermal films can withstand rupture. In vitro drug dissolution study indicates maximum amount of drug $96.8 \%$ (F2) released in $24 \mathrm{~h}$ when compared with marketed formulation $84.81 \%$. The release order follows Fickian diffusion. The formulation F2 was optimized based on drug flux, permeability coefficient and enhancement ratio.
\end{abstract}

Keywords: Benazepril Hydrochloride, Transdermal films, Hypertension, Eudragit, Plasticizer, Penetration enhancer, Permeation.

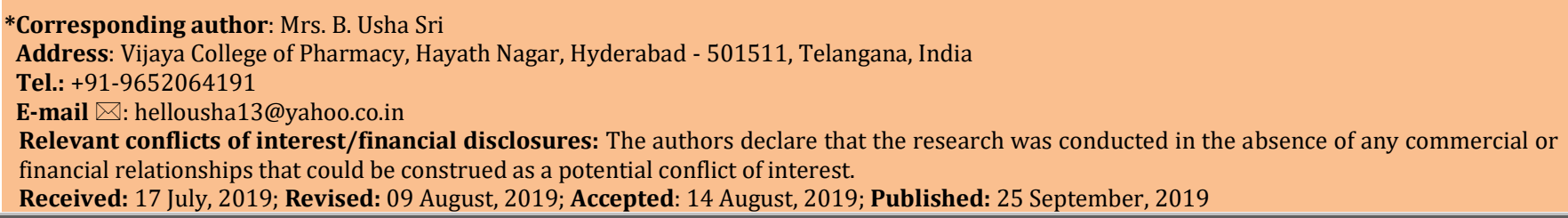

\section{INTRODUCTION}

Transdermal drug delivery systems (TDDS) are systems that deliver the loaded drug across a patient's skin by placing adhesive patch on the skin that induces drug into blood streams directly. [1-2] The TDDS is a transport process through a multi-laminar structure, e.g. from the patch to stratum corneum and finally penetrating into the blood. ${ }^{[3-4]}$ The advantages of TDDS is that the drug is induced directly in the blood stream without entering various defense systems. [5] The TDDS do not undergo drug degradation in GI and first-pass drug metabolism within the liver. Drugs like estradiol (estrogen) [6] or paracetamol [7] causes side-effects like liver damages which can be suppressed by the use of TDDS for effective oral administration. These systems minimize drug side effects, increase patients' 
acceptance and require lesser drug dosage. The other advantages of TDDS include increase in therapeutic efficacy and sustained plasma level of drug. The developments of TDDS involves selection of drug, evaluation of drug flux formulation of drug, analysis of physicochemical and stability factors, consideration of patients compliance and economy. The TDDS are multi layered polymeric formulations containing drug sandwiched between polymeric layers, an outer layer to overcome the loss of drug through the backing surface and an inner layer that works as an adhesive. Benazepril is anti hypersensitive drug which is considered as primary treatment for high blood pressure. ${ }^{[8]}$ It is administrated orally in combinations Benazepril/hydrochlorothiazide and Benazepril/ amlodipine. Benazepril inhibits ACE by reducing reninangiotensin-aldosterone system activity.

\section{MATERIAL AND METHODS}

\section{Materials}

The drug Benazepril Hydrochloride is kindly sponsored by Aurobindo Pharma Ltd., Hyderabad. HPMC E 15, Eudragit RS 100 and Eudragit RDL were obtained from Dr. Reddy's Laboratories Ltd., Hyderabad. Polyethylene glycol 400, Dimethyl Formamide, Dichloro methane, methanol, Sodium hydroxide and monopotassium phosphate were procured from Finar labs ltd, Mumbai.

\section{Formulation of Benazepril Hydrochloride} transdermal films

The Benazepril Hydrochloride transdermal formulations prepared by film casting technique using liquid Paraffin as lubricant. [9] All the polymers (HPMC E15, ERL 100 and ERS100) dissolved in solvent system for homogenous solution followed by ultra sonication. The drug added to the contents with continuous stirring followed by addition of plasticizer and penetration enhancer. The resultant solution lubricated with paraffin, poured into petri dish, solvent allowed to evaporate to obtain Benazepril polymer matrix. Air entrapped in the polymeric solutions created a problem in casting films; swelling of polymers required time (Table 1).

Evaluation of Benazepril Hydrochloride transdermal films

Physical Appearance

All the prepared 11 formulations inspected for physical appearance visually.

\section{Weight uniformity}

Weight uniformity is calculated by weighing selected patches in triplets. The average weight and standard deviation is calculated for each formulation. [10]

\section{Thickness uniformity}

The thickness of Benazepril Hydrochloride transdermal films is measured at five various points using screw gauge. The average of all the observations tabulated. [11] Drug content uniformity

The transdermal films were dissolved in suitable solvent for $24 \mathrm{~h}$ with constant stirring. The amount of drug was analyzed by UV-Visible Spectrophotometer at $294 \mathrm{~nm}$. [12]

Water vapour transmission (WVT) studies

WVT was measured by fixing the transdermal films over the brim of transmission cells containing fused $\mathrm{CaCl}_{2}$. The initial weight of cells noted, placed in desiccators containing $200 \mathrm{ml}$ of $\mathrm{KCl}$ solution. The cells removed from desiccators every consecutive day till seven days and weighed. [13] WVT Rate calculated using the formula

Rate of WVT $=\mathrm{W} \times \mathrm{L} / \mathrm{S}$

Where $W$ stands for the amount of water transmitted in gm, L stands for thickness of the film and $S$ for surface area of exposed film

Folding Endurance

Folding Endurance is the logarithm (to the base of ten) of the number of folds that are required break the test piece under normal conditions. [14]

In-vitro drug permeation study

The formulated transdermal patch membranes are placed in compartment of diffusion cell [15] between receptor and donor. The transdermal system is applied to the hydrophilic side of the membrane and then mounted in the diffusion cell with lipophillic side in contact with receptor fluid. The samples drawn at regular time intervals, diluted and absorbance is analyzed spectrophotometrically.

Stability studies

The stability of optimized formulations checked at $40^{\circ} \mathrm{C}$ /75\% RH for a period of 90 days. The Transdermal films of $3.14 \mathrm{~cm}^{2}$ were packed in aluminum foils and placed on petridish and stored at $40^{\circ} \mathrm{C} \pm 2{ }^{\circ} \mathrm{C} / 75 \% \mathrm{RH}$ $\pm 5 \%$ for three month. After the prescribed time periods the samples evaluated for in vitro drug release, drug content, thickness and weight uniformity. [16]

\begin{tabular}{cccccccc}
\multicolumn{2}{c}{ Table 1: Benazepril Hydrochloride } & TDDS & formulations \\
\hline Code & $\begin{array}{c}\text { Amt of } \\
\text { Drug } \\
\left(\mathbf{m g} / \mathbf{c m}^{2}\right)\end{array}$ & $\begin{array}{c}\text { HPMC } \\
\mathbf{( m g )}\end{array}$ & $\begin{array}{c}\text { ERL } \\
\mathbf{1 0 0} \\
\mathbf{( m g )}\end{array}$ & $\begin{array}{c}\text { ERS } \\
\mathbf{1 0 0} \\
\mathbf{( m g )}\end{array}$ & $\begin{array}{c}\text { PEG } \\
\mathbf{4 0 0} \\
\mathbf{( \% )}\end{array}$ & $\begin{array}{c}\text { DMF } \\
\mathbf{( \% )}\end{array}$ & $\begin{array}{c}\text { DCM : } \\
\text { Methanol } \\
\mathbf{1 : 1}(\mathbf{m l})\end{array}$ \\
\hline F1 & 4 & 800 & 200 & - & 15 & 8 & 6 \\
F2 & 4 & 600 & 400 & - & 15 & 8 & 6 \\
F3 & 4 & 400 & 600 & - & 15 & 8 & 6 \\
F4 & 4 & 200 & 800 & - & 15 & 8 & 6 \\
F5 & 4 & - & 1000 & - & 15 & 8 & 6 \\
F6 & 4 & 800 & - & 200 & 15 & 8 & 6 \\
F7 & 4 & 600 & - & 400 & 15 & 8 & 6 \\
F8 & 4 & 400 & - & 600 & 15 & 8 & 6 \\
F9 & 4 & 200 & - & 800 & 15 & 8 & 6 \\
F10 & 4 & - & - & 1000 & 15 & 8 & 6 \\
F11 & 4 & 600 & 200 & 200 & 15 & 8 & 6 \\
\hline
\end{tabular}

\section{RESULTS}

Formulation and evaluation of Benazepril hydrochloride transdermal films

Eleven formulations were prepared with varying compositions of polymers (The polymers HPMC E15, ERL 100, ERS 100), plasticizers (PEG 400), penetrating enhancer (DMF) and solvents (DCM, methanol). All the eleven formulations were checked for physico chemical parameters. [17]

Evaluation of Benazepril hydrochloride transdermal films 
B. Usha Sri et al. / Formulation and Evaluation of Benazepril Hydrochloride Transdermal Films.

Table 2: The physico-chemical evaluation of Benazepril hydrochloride transdermal films

\begin{tabular}{|c|c|c|c|c|c|}
\hline FC & Weight uniformity (mg) & Thickness uniformity (mm) & $\begin{array}{c}\text { Drug content } \\
\text { uniformity }(\%)\end{array}$ & $\begin{array}{c}\text { WVT } \\
\left(\mathrm{gcm} / \mathrm{cm}^{2} \cdot 24 \mathrm{~h}\right)\end{array}$ & $\begin{array}{c}\text { Folding } \\
\text { Endurance }\end{array}$ \\
\hline F1 & $125.0 \pm 1.82$ & $0.18 \pm 0.0021$ & $98.86 \pm 4.5$ & $6.91 \pm 0.059$ & $271 \pm 4.35$ \\
\hline F2 & $138.6 \pm 1.76$ & $0.19 \pm 0.0032$ & $98.95 \pm 1.9$ & $6.75 \pm 0.055$ & $308 \pm 3.13$ \\
\hline F3 & $141.2 \pm 2.30$ & $0.25 \pm 0.0058$ & $97.13 \pm 2.6$ & $6.63 \pm 0.035$ & $259 \pm 5.21$ \\
\hline $\mathrm{F} 4$ & $149.5 \pm 2.54$ & $0.30 \pm 0.0027$ & $98.95 \pm 4.1$ & $6.42 \pm 0.024$ & $248 \pm 3.86$ \\
\hline F5 & $150.0 \pm 1.35$ & $0.40 \pm 0.0024$ & $98.40 \pm 3.4$ & $6.25 \pm 0.029$ & $246 \pm 4.60$ \\
\hline F6 & $100.0 \pm 1.92$ & $0.20 \pm 0.0041$ & $96.84 \pm 3.7$ & $5.98 \pm 0.037$ & $315 \pm 4.13$ \\
\hline F7 & $125.1 \pm 2.41$ & $0.18 \pm 0.0031$ & $97.30 \pm 4.8$ & $5.92 \pm 0.021$ & $288 \pm 3.88$ \\
\hline F8 & $131.4 \pm 2.13$ & $0.22 \pm 0.0023$ & $98.62 \pm 2.5$ & $5.55 \pm 0.048$ & $298 \pm 5.05$ \\
\hline F9 & $136.7 \pm 1.84$ & $0.10 \pm 0.0042$ & $97.78 \pm 1.6$ & $5.18 \pm 0.034$ & $294 \pm 5.13$ \\
\hline F10 & $138.2 \pm 1.25$ & $0.31 \pm 0.0036$ & $97.55 \pm 2.7$ & $4.90 \pm 0.030$ & $289 \pm 4.51$ \\
\hline F11 & $140.0 \pm 2.34$ & $0.22 \pm 0.0027$ & $96.98 \pm 1.6$ & $4.79 \pm 0.051$ & $285 \pm 5.01$ \\
\hline
\end{tabular}

Table 3: In-vitro drug permeation studies of Benazepril hydrochloride TDDS formulation

\begin{tabular}{ccccccccc}
\hline \multirow{2}{*}{ FC } & \multicolumn{7}{c}{ Time (h) } \\
\cline { 2 - 9 } & $\mathbf{0 h}$ & $\mathbf{2 h}$ & $\mathbf{4 h}$ & $\mathbf{6 h}$ & $\mathbf{8 h}$ & $\mathbf{1 0 h}$ & $\mathbf{1 2 h}$ & $\mathbf{2 4 h}$ \\
\hline F1 & 0 & 10.38 & 26.4 & 35.4 & 47.2 & 53.9 & 65.6 & 95.6 \\
F2 & 0 & 12.2 & 28.9 & 39 & 49.7 & 57.85 & 64.7 & 96.8 \\
F3 & 0 & 6.4 & 15.4 & 29.9 & 41.4 & 50.2 & 61.4 & 85.17 \\
F4 & 0 & 1.87 & 5.17 & 10.1 & 14.6 & 18.9 & 23.5 & 74.3 \\
F5 & 0 & 0.8 & 5.3 & 7.5 & 10.4 & 13.5 & 15.7 & 53.2 \\
F6 & 0 & 8.1 & 35.4 & 39.9 & 47.4 & 59.7 & 65.6 & 92.3 \\
F7 & 0 & 7.2 & 18.9 & 30.4 & 44.8 & 53.9 & 62.3 & 80.5 \\
F8 & 0 & 4.6 & 14.1 & 28.6 & 40.3 & 51 & 60.6 & 71 \\
F9 & 0 & 3.12 & 6.2 & 13 & 38.1 & 43.7 & 52.6 & 64.7 \\
F10 & 0 & 0.67 & 4.2 & 6.9 & 10.5 & 11.1 & 19.2 & 41.4 \\
F11 & 0 & 5.4 & 17.1 & 27.3 & 43.7 & 56.9 & 62.1 & 70.9 \\
\hline
\end{tabular}

\section{Physical appearance}

The transdermal films of all eleven formulations were thin, transparent, flexible, smooth and uniform. Incorporation of PEG 400 yielded smooth and flexible patches. The transparent nature of films may be more prominently attributed to ERL than ERS. The flexibility can be due to HPMC.

Weight uniformity

The weights of all formulations are uniform. The values of all formulations vary from $100 \pm 1.92 \mathrm{mg}$ to $150 \pm$ $1.35 \mathrm{mg}$ with F6 showing the minimum variation (Table 2).

\section{Thickness uniformity}

The film thickness ensured uniformity of thickness in all developed formulation. The value ranges from $0.1 \pm$ $0.0042 \mathrm{~mm}$ to $0.3 \pm 0.0027 \mathrm{~mm}$ (Table 2).

\section{Drug content uniformity}

The transdermal films were dissolved in suitable solvent for $24 \mathrm{~h}$ with constant stirring. The amount of drug present was determined by U.V Spectrophotometer at $294 \mathrm{~nm}$. [12]

Water vapour transmission (WVT)

The WVT of all the formulations vary between $4.79 \pm$ 0.051 to $6.91 \pm 0.059 \mathrm{gcm} / \mathrm{cm}^{2} 24 \mathrm{~h}$. ERL film formulations exhibited good water vapour permeation than that of ERS. There was a decrease in Water vapour transmission with increasing film thickness and crosslink density, due to the increased path length for diffusion and increased film rigidity at higher crosslink densities (Table 2).

\section{Folding Endurance}

The values of all eleven formulation range between 246 \pm 4.60 to $315 \pm 4.13$. The amount of drug released from transdermal film formulations after 24 hours were $96.8 \%, 95.6 \%, 92.3 \%, 85.17 \%, 80.5 \%, 74.3 \%, 71 \%, 70.9 \%$, $64.7 \%, 53.2 \%, 41.4 \%$ respectively. [18] The highest \% release from $\mathrm{F} 2$ formulation due to the presence of Eudragit and HPMC in almost equal proportions suggesting HPMC is required for the control of rate and Eudragit for the release for sustained and prolonged effect (Table 3).

Release order kinetics

The drug dissolution data fitted into various release order kinetics plots. The slope (n) indicate that the drug released by Fickian diffusion (Figure 1-4).

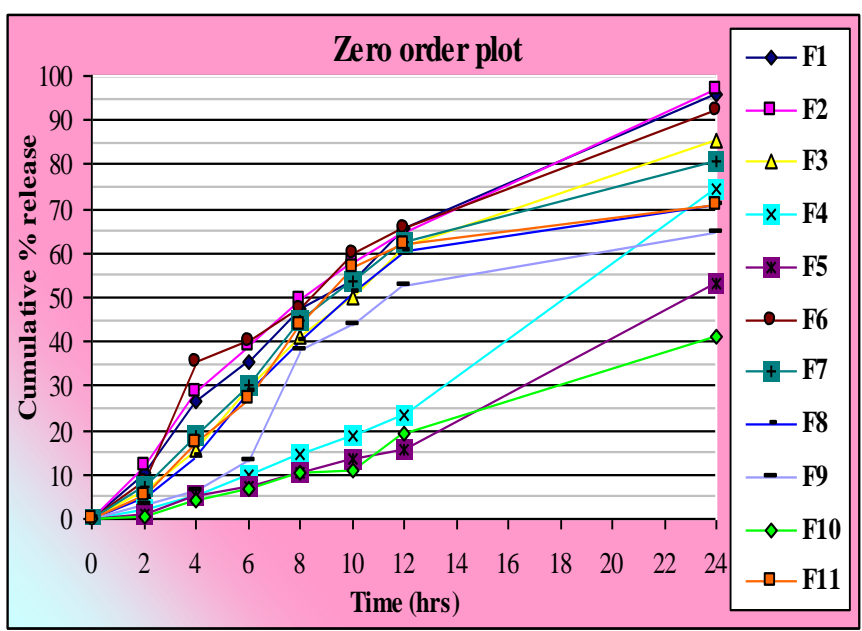

Fig. 1: Zero order kinetics plot of Benazepril hydrochloride transdermal formulation

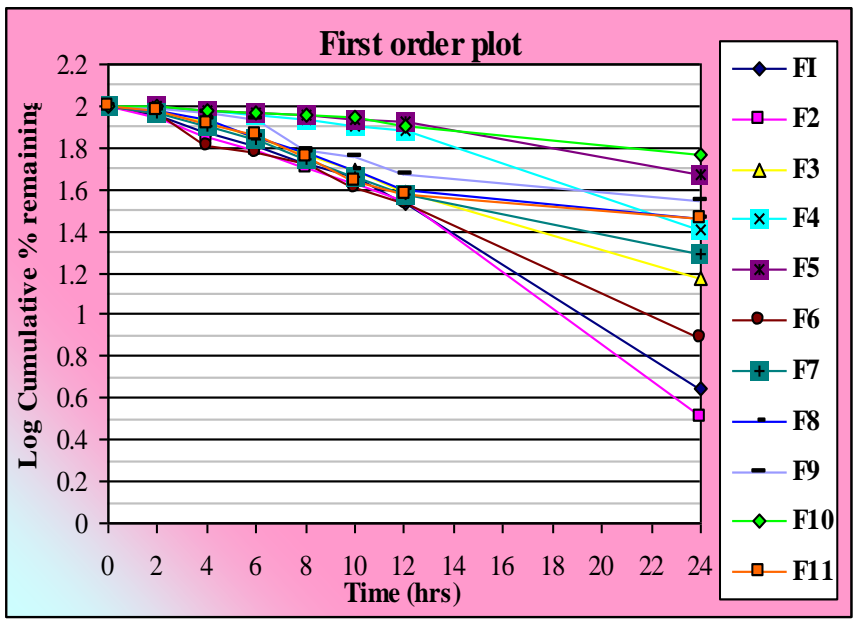

Fig. 2: First order kinetics plot of Benazepril hydrochloride transdermal formulation 


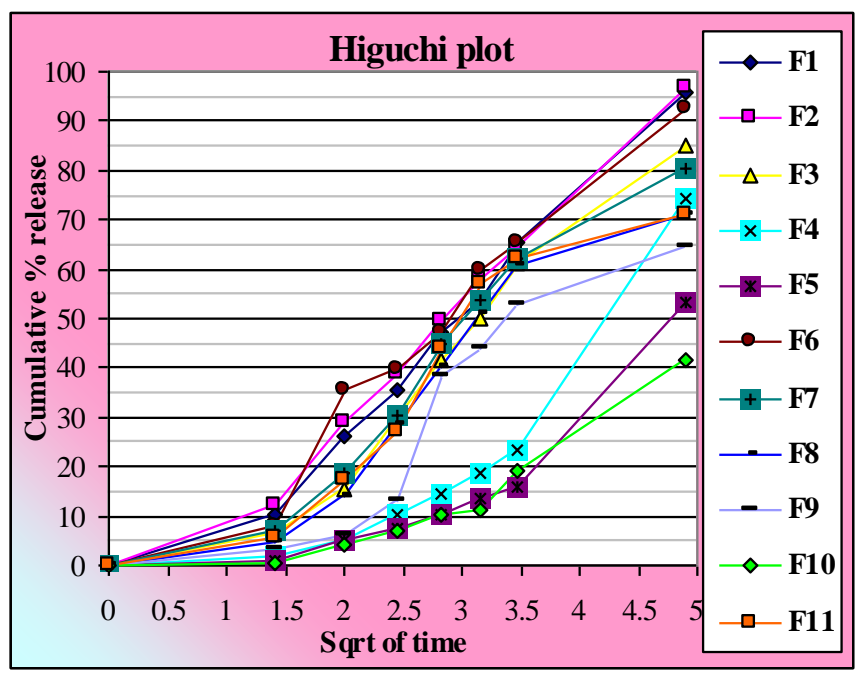

Fig. 3: Higuchi plot of Benazepril hydrochloride transdermal formulation

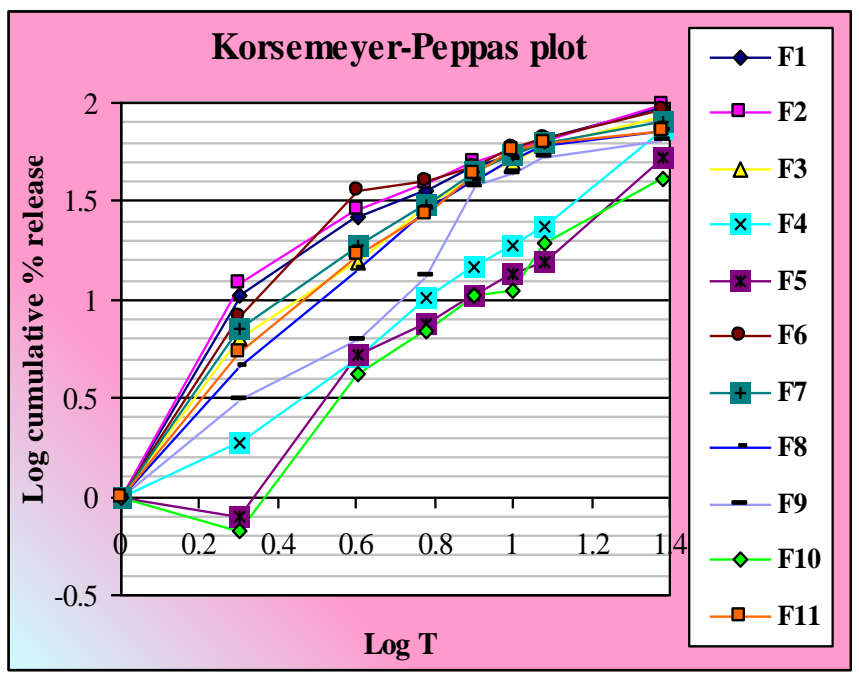

Figure 4: Korsemeyer peppas plot of Benazepril hydrochloride transdermal formulation

Table 4: Stability study data of Benazepril hydrochloride transdermal formulation

\begin{tabular}{ccccc}
\hline \multirow{2}{*}{ Formulation } & \multicolumn{4}{c}{ Time Period } \\
\cline { 2 - 5 } & Initial & 1 month & 2 months & 3 months \\
\hline F1 & 98.86 & 98.72 & 97.53 & 97.40 \\
F2 & 97.92 & 97.85 & 97.79 & 97.71 \\
F3 & 97.13 & 97.02 & 97.00 & 96.97 \\
F4 & 98.95 & 98.78 & 98.34 & 98.11 \\
F5 & 98.4 & 98.05 & 98.00 & 97.86 \\
F6 & 96.84 & 96.65 & 96.34 & 96.11 \\
F7 & 97.30 & 97.23 & 97.00 & 96.76 \\
F8 & 98.62 & 98.12 & 97.86 & 97.23 \\
F9 & 98.78 & 98.34 & 98.11 & 98.00 \\
F10 & 98.55 & 98.24 & 98.01 & 97.90 \\
F11 & 96.98 & 96.54 & 96.31 & 96.20 \\
\hline
\end{tabular}

\section{Accelerated stability studies}

No physical changes in appearance, flexibility and colour were observed. The degradation with respect to drug content was observed negligible (Table 4).

Permeation Data Analysis

The flux values calculated for formulation F4, F5 and F2 meets the required flux of $14.08 \mu \mathrm{g} / \mathrm{cm}^{2} / \mathrm{h}$ (control). The highest flux of $89.11 \mu \mathrm{g} / \mathrm{cm}^{2} / \mathrm{h}$ was recorded for $\mathrm{F} 1$ formulation.
The permeability coefficient value ranges from 5.67 $\mathrm{cm} / \mathrm{h}$ to $14.96 \mathrm{~cm} / \mathrm{h}$. The minimum value recorded for F2 that is in close relation with the permeability coefficient of the control $(5.50 \mathrm{~cm} / \mathrm{h})$.

Enhancement ratio values of all formulations ranges from 1.03 to 2.72 with minimum value recorded for formulation F2 (Table 5). Hence Formulation F2 is considered as optimized formulation and subjected to drug compatibility study through FTIR.

Table 5: Permeability parameters of Benazepril hydrochloride transdermal formulation

\begin{tabular}{cccc}
\hline $\begin{array}{c}\text { Formulation } \\
\text { code }\end{array}$ & $\begin{array}{c}\text { Drug flux } \\
\text { (permeation rate) at } \\
\text { steady state(Jss) }\end{array}$ & $\begin{array}{c}\text { Permeability } \\
\text { Coefficient } \\
\text { (cm/h ) }\end{array}$ & E $_{\mathbf{r}}^{* *}$ \\
\hline Control & 14.08 & 5.50 & 1 \\
F1 & 89.11 & 14.96 & 2.72 \\
F2 & 2.53 & 5.67 & 1.03 \\
F3 & 50.8 & 13.99 & 2.54 \\
F4 & 12.38 & 11.68 & 2.12 \\
F5 & 3.75 & 9.28 & 1.68 \\
F6 & 65.35 & 14.23 & 2.58 \\
F7 & 53.84 & 13.19 & 2.39 \\
F8 & 31.45 & 12.05 & 2.19 \\
F9 & 20.26 & 11.46 & 2.08 \\
F10 & 89.08 & 14.87 & 2.70 \\
F11 & 43.36 & 12.04 & 2.18 \\
\hline
\end{tabular}

*Drug flux units $-\mu \mathrm{g} / \mathrm{cm} 2 / \mathrm{h}$; ${ }^{* *} \mathrm{Er}$-Enhancement ratio
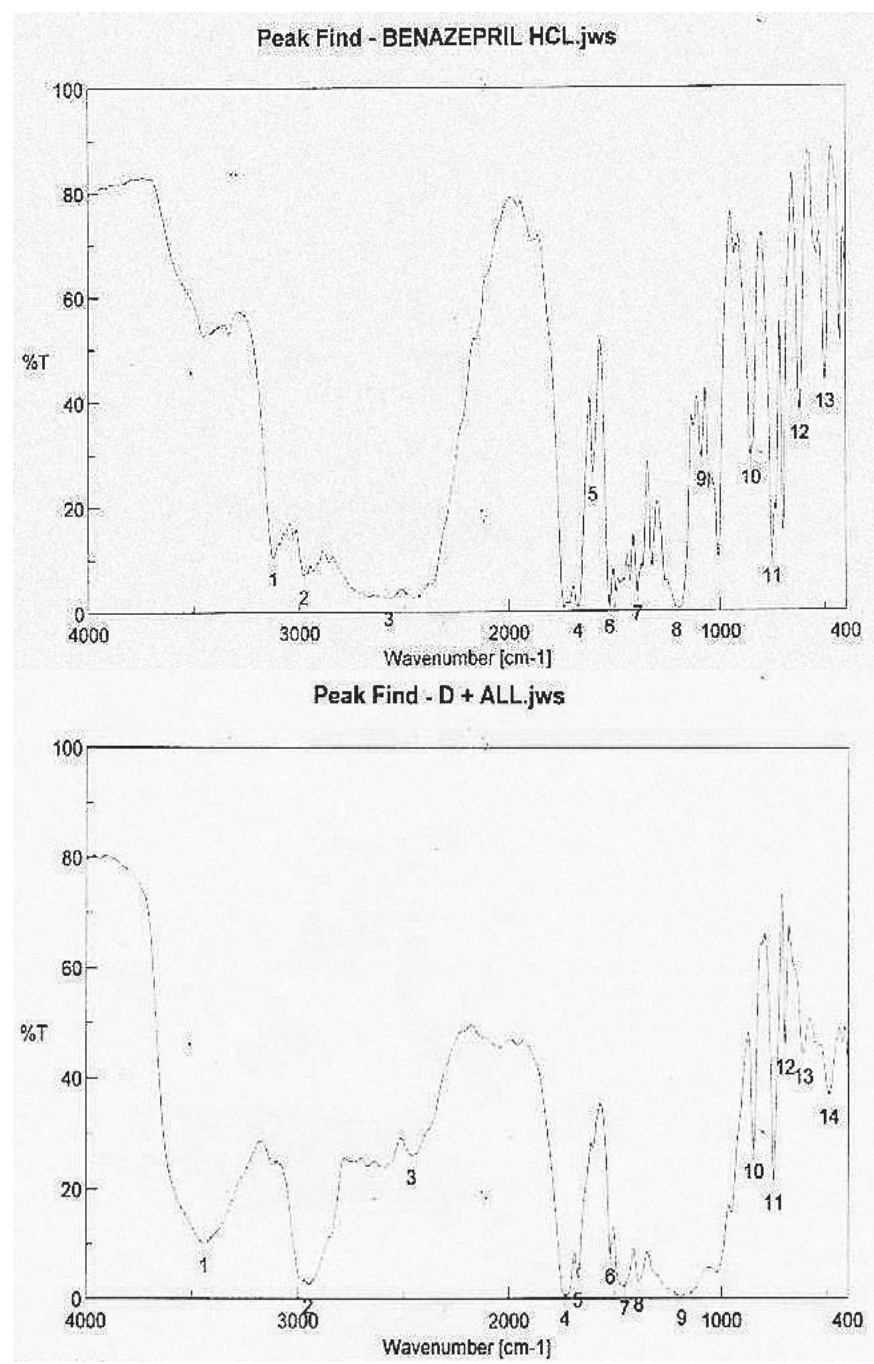

Fig. 5: FTIR of Benazepril Hydrochloride and optimized formulation F2 


\section{Drug compatibility study}

Benazepril exhibits 3 principle peaks at $1739 \mathrm{~cm}^{-2}$ due to $-\mathrm{C}=\mathrm{O}$ of $-\mathrm{C}-\mathrm{CO}-\mathrm{OCH}_{2} \mathrm{CH}_{3}, 1674 \mathrm{~cm}^{-2}$ due to $-\mathrm{COOH}$, $1211 \mathrm{~cm}^{-2}$ due to $-\mathrm{CH}$ bending. The same characteristic peaks were shown by the pure drug as that of monograph ensuring its purity. It was observed that characteristic IR absorption peaks of Benazepril were not altered in formulation F2. This indicates the drug is compatible and stable in the formulation (Figure 5).

Comparative drug release study of optimized Benazepril Hydrochloride transdermal formulation (F2) and marketed formulation

The drug dissolution profiles of Benazepril optimized transdermal formulation and marketed tablet formulation were comparable without any significant difference. The drug release at the end of $24 \mathrm{~h}$ was found to be $96.8 \%$ and $84.81 \%$ for optimized and marketed formulations respectively (Figure 6).

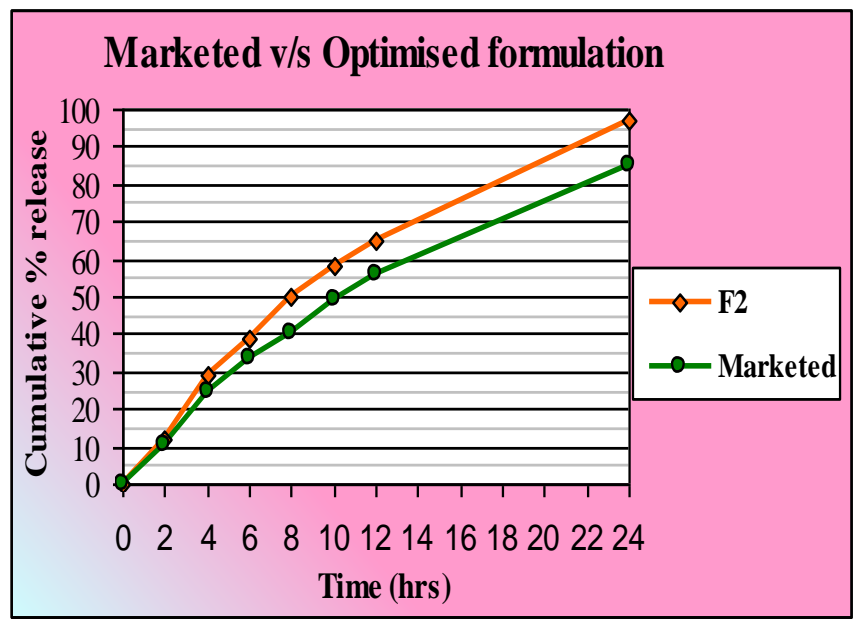

Fig. 6: Comparative in-vitro study plot of optimized transdermal formulation (F2) and conventional marketed tablet formulation

\section{DISCUSSION}

The results of Benazepril transdermal films indicate that these TDDS systems provide better compliance than existing conventional drug delivery system. The transdermal films of Benazepril Hydrochloride formulated using HPMC E15, ERL 100, ERS100 and subjected to physicochemical evaluation followed by in vitro study. The physico chemical properties shown by all formulations were satisfactory. The prepared patches were permeable to water vapour depending upon the thickness and crosslink density. F2 formulation was the best formulation as per the diffusion profile. The Permeation Data Analysis also reveals that the formulation F2 have comparable Drug flux, Permeability Coefficient and Enhancement ratio with the control. Hence innovative and promising transdermal drug delivery formulation of Benazepril Hydrochloride was developed for the effective treatment of hypertension.

\section{REFERENCES}

1. Chien YW. Novel drug delivery systems. Drugs and the Pharmaceutical Sciences, Marcel Dekker, New York, NY, 1992; 797, pp.301-381.

2. Anna Wokovich M. Transdermal drug delivery system (TDDS) adhesion as a critical safety, efficacy and quality attribute. Eur J Pharm Biopharm. 2006;64(1):1-8.

3. Cleek RL, Bunge AL. A new method for estimating dermal absorption from chemical exposure. General approach. Pharm Res. 1993;1(10): 497-506.

4. Vinod KR, Sravani P, David Banji, Teja BB. Transdermal Drug Delivery System-Overcoming Challenges of Popular Drug Delivery Systems. IJPWR. 2010;1(3):25-32

5. Vyas SP, Khar RK. Targeted and Controlled drug delivery. Edn 1, CBS, Publisher and distributors, New Delhi, 2002.

6. Cramer MP, Saks SR. Translating safety, efficacy and compliance into economic value for controlled release dosage forms. Pharmaco Economics 1994;5(6):482-504.

7. Sheen CL, Dillon JF, Bateman DN, Simpson KJ, Macdonald TM. Paracetamol toxicity: epidemiology, prevention and costs to the health-care system.Q J Med. 2002;95(9):609-19.

8. Mustsuo O. Skin permeability of water soluble drugs. Chem Pharma Bull. 1995;37(5): 1404-1405.

9. Ramesh Gannu, Vamshi Vishnu Y, Kishan V, Madhusudhan Rao Y. Development of nitrendipine transdermal patches: in vitro and ex vivo characterization. Current Drug Delivery 2007;4 (1):69-76.

10. Samanta MK, Dube R, Suresh B. Transdermal drug delivery system of haloperidol to overcome self induced extrapyramidal syndrome. Drug Dev Ind Pharm2003;29:405415.

11. Lewis S, Pandey S, Udupa N. Design and evaluation of matrix type and membrane controlled transdermal delivery systems of nicotine suitable for use in smoking cessation. Ind J Pharm Sci. 2006;68:179-184.

12. Costa P, Ferreria DC, Morgado R, Sousa Lobo JM. Design and evaluation of a lorazepam transdermal delivery system. Drug Dev Ind Pharm. 1997;23:939-944.

13. Rao PR, Diwan PY. Permeability studies of cellulose acetate free films for transdermal use: Influence of plasticizers, Pharm Acta Helv. 1997;72: 47-51.

14. Ubaidulla U, Reddy MV, Ruckmani K, Ahmad FJ, Khar RK. Transdermal therapeutic system of carvedilol: Effect of hydrophilic and hydrophobic matrix on in vitro and in vivo characteristics. AAPS Pharm SciTech. 2007;8(1):13-20.

15. Elias PM. Lipids and the epidermal permeability barrier. Arch Dermatol. 1981;270:95-117.

16. Panchagnula R, Bokalial R, Sharma P, Khandavilli S. Transdermal delivery of naloxone: skin permeation, pharmacokinetic, irritancy and stability studies. Int J Pharm. 2005;293: 213-223.

17. Lewis S, Pandey S, Udupa N. Design and evaluation of matrix type and membrane controlled transdermal delivery systems of nicotine suitable for use in smoking cessation. Ind J Pharm Sci. 2006;68:179-184.

18. Sood A, Panchagnula R. Role of dissolution studies in controlled release drug delivery system. STP Pharma Sci. 1999;9:157-168. 